\title{
RAZA, NOVELA DE JAIME DE ANDRADE, PSEUDÓNIMO DE FRANCISCO FRANCO
}

\author{
Rafael UTRERA MACÍAS
}

Universidad de Sevilla

\section{RESUMEN}

Raza, más allá de su valoración literaria, es un texto insólito por cuanto ningún jefe de estado o de gobierno en pleno ejercicio de su autoridad ha justificado su victoria por medio de una ficción donde, además, él mismo está visiblemente representado; menos aún que la novela sea algo provisional por estar destinada a convertirse en documento cinematográfico que, al tiempo, se ofrece como paradigma ejemplar en el contexto social de un estado autárquico. Este primerizo trabajo literario, entre sublimaciones argumentales e idealizaciones de personajes, establece, por medio de la ficción y con evidente huida de una realidad nociva para su honor, las líneas dramáticas de su «compromiso moral» según los conceptos de patria, nación, lealtad, etc., los cuales sustentan las bases de su personal ideograma vital. Lejos de formas literarias cercanas a la deshumanización del arte, como las generaciones de escritores coetáneos iban a establecer, el novelista se orienta hacia la expresión realista, si bien adornada con efectos de una retórica florida que aspira a funcionar como prosa de inspiración culterana.

Palabras clave: Raza, Jaime de Andrade, Francisco Franco, novela.

\begin{abstract}
Raza is, beyond its literary merit, an unusual text, since it is the first time that a chief of government justifies his victory in a fiction where himself is represented. In addition, the novel was destined to turn into cinematographic document, which is offered as example in the social context of an autarkic state. By means of the fiction, this first literary work establishes the main points of the moral commitment of the author, according to the concepts of mother land, nation, loyalty, etc.
\end{abstract}

Key words: Raza, Jaime de Andrade, Francisco Franco, novel. 


\section{ANECDOTARIO QUE DA LUGAR A UN GUIÓN. EDICIONES}

Raza. Anecdotario para el guión de una película es un texto escrito, con el pseudónimo de Jaime de Andrade, por Francisco Franco Bahamonde, autoproclamado, tras su victoria militar en 1939, Jefe de Gobierno y Jefe del Estado Español. Los deseos del Caudillo de ver su trabajo literario resuelto en la pantalla convirtieron en productora al Consejo de la Hispanidad, en guionistas a Antonio Román y a José Luis Sáenz de Heredia y a éste último en director; los asesores fueron el novelista Manuel Halcón y el periodista Manuel Aznar. Alfredo Mayo, Ana Mariscal, José Nieto y Blanca de Silos interpretaron los principales papeles. El estreno oficial de Raza $a^{1}$ tuvo lugar en Madrid el 5 de enero de 1942 en el Palacio de la Música.

En mayo de este año se publicó, por parte de Ediciones Numancia, una simbólica edición de quinientos ejemplares. Posteriormente, en 1945, cuando la película se había estrenado en numerosas ciudades españolas y ya no era ningún secreto la autoría del original, aparecerá una segunda bajo el sello de la misma editorial y al cuidado de Ediciones de la Vicesecretaría de Educación Popular. Las doscientas dos páginas que la integran fueron impresas en los talleres Diana (c/ Larra 6, Madrid). El nombre del autor, Jaime de Andrade, el título, Raza, y el término Novela combinan mayúsculas y minúsculas en diferente tipografía. La sobrecubierta ya utiliza una iconografía estrechamente relacionada con la película; así en la portada, aparece, de fondo, un arco de triunfo en cuyo frontal se lee «Victoria»; bajo un ángel, el soldado ecuestre empuña la espada y porta una bandera; acompañada de su hijo, una madre saluda brazo en alto al guerrero. Por su parte, la contraportada ofrece un dibujo de marinero uniformado que abraza, y es abrazado, por su esposa; alrededor, sus hijos, dos varones y una niña; un tercero, mayor, separado, abatido, abraza una caja o jaula. Precio del volumen: 10 pesetas. La obra se cierra con la fecha de edición, 16 de marzo de 1945, y el consabido Laus Deo. Francisco Franco entrará en 1964, según informaba el diario ABC (26 de febrero de 1964) en la Sociedad General de Autores como autor de la novela².

1. Una nueva versión de esta misma película, con arreglos técnicos y supresiones diversas, fue estrenada en 1950 bajo el título El espíritu de una raza. La comparación entre ambas evidencia las notables diferencias y, sobre todo, el distinto sentido político que las distancia en función de la evolución del contexto histórico. Su análisis cinematográfico ha sido abordado desde variados enfoques. La lectura de Román Gubert (1977) se constituyó en guía de lectura por cuanto analiza la película desde una perspectiva freudiana y psicoanalítica. Como contestación política a la misma, véase Ricardo de la Cierva (1997). La película Raza: el espiritu de Franco (1979), de Jorge Herralde, toma como punto de partida el texto de Román Gubert y procede a una reconstrucción de la película de Sáenz de Heredia seleccionando como testigos de su discurso a personas vinculadas al general (su hermana) o al filme (un actor).

2. Su obra precedente, firmada como Comandante Franco (1922), fue reeditada en 1939, si bien con censura en algunos pasajes (Gubert, 1977:177). Aparte de estos títulos, Franco escribió artículos en órganos profesionales como Revista de Tropas Coloniales durante los años veinte, mientras que, al final 


\section{JAIME DE ANDRADE/FRANCISCO FRANCO EN EL CONTEXTO DE LA NOVELÍSTICA COETÁNEA}

Raza debió de escribirse entre dos fechas concretas: el Desfile de la Victoria, celebrado el 19 de mayo de 1939 y el comienzo del rodaje del filme, 31 de julio de 1941. Así sería al margen de las notas que el autor tuviera redactadas en fechas anteriores. Según Ricardo de la Cierva, «se escribió en el invierno de 1940-1941, año y medio después de terminada con éxito la guerra civil y como un desahogo en medio de las preocupaciones de la segunda guerra mundial» (1997:13).

De las dos denominaciones, la primera, «anecdotario para el guión de una película», responde al subtítulo utilizado por el autor cuando, en un momento inicial, redacta su trabajo para ser el texto literario de un futuro guión cinematográfico; la segunda, «novela», es el término utilizado con posterioridad al estreno de la película para precisarle al lector el carácter y género de la obra. Jaime de Andrade, es decir, Francisco Franco, añade a sus conocidas actividades artísticas (fundamentalmente la de pintor) las de guionista y novelista. Cualquier volumen temático, base de datos, etc., registra aquel término; algunos historiadores de la literatura incluyen al autor en el contexto de su generación.

Si atendemos a la cronología del nacimiento, Jaime de Andrade / Francisco Franco quedaría encuadrado entre la generación de 1914 y los coetáneos a la generación de 1927. A la primera pertenecerían, entre otros, Corpus Barga (1887), Ramón Gómez de la Serna (1888) y Benjamín Jarnés (1888); a la segunda, en subjetiva selección, Arturo Barea (1897), Manuel D. Benavides (1895), Rosa Chacel (1898), Pedro Salinas (1891) y Rafael Sánchez Mazas (1894) (Basanta, 1981:7). El autor de Raza nació en 1892, por lo que se situaría en la línea divisoria entre ambas.

Gonzalo Sobejano (1975: 54) ha catalogado a los novelistas de la guerra civil en tres apartados: a) observadores: Agustín de Foxá, Tomás Borrás. b) militantes: Rafael García Serrano, Fernández de la Reguera. c) intérpretes, agrupados en exiliados: Arturo Barea, Max Aub, Paulino Massip, Manuel Andújar; y no exiliados: Gironella, Lera, Romero. Bajo esta perspectiva, Andrade/Franco cumple los tres requisitos, ya que es observador, militante e intérprete al tiempo: su guión/novela funciona antonomásticamente por cuanto un general insurrecto, triunfador en la guerra, victorioso en la paz, reflexiona y escribe para ofrecer un relato literario que debe convertirse en ejemplar modelo cinematográfico.

Por su parte, Eugenio de Nora en La novela española contemporánea, dedica un capítulo a estudiar el impacto de la guerra española en la novela y cita diversos

de los cuarenta, se dice que el autor de otros publicados en el diario Arriba con el seudónimo Jakin Boor. Sobre esta atribución, véase De la Cierva (1997:12). 
autores con títulos cercanos cronológicamente a Raza: Madrid, de corte a checa (1938), de Agustín de Foxá, Eugenio, o proclamación de la primavera (1938), de Rafael García Serrano, La mascarada trágica (1940), de Enrique Noguera, Leoncio Pancorbo (1942), de José M. a Alfaro y La fiel infantería (1943), de Rafael García Serrano. Asimismo, señala los numerosos aficionados que «intentan pasar por escritores» (Nora, 1963, II: 55), cuantos encuentran el núcleo básico de su inspiración en la guerra civil, «en sus variadas vertientes de contienda ideológica, confrontación política y social de clases y tendencias y, en fin, lucha armada cívico-militar» (58) así como la dominante adscripción «a las técnicas y formas narrativas realistas, su consciente compromiso político y moral, y su ruptura decidida con la deshumanización del arte» (60). La declarada militancia de estos escritores le impide al crítico la discriminación imparcial de los valores puramente estéticos. En relación a algunos títulos de Rafael García Serrano, el ensayista establece referencias de género e intención susceptibles de mostrar cercanía a Raza:

Tomadas, pues, no como novelas (aun en el sentido más moderno de la palabra), sino como creaciones literarias marginales al género, aunque excediendo al reportaje y al simple testimonio autobiográfico, La fiel infantería, como reflejo de la juventud combatiente, y Plaza del Castillo, como film (sic) partidista y local de las jornadas que preceden al 18 de julio en una capital de provincia típica (Pamplona entre el 6 y el 19 de julio de 1936), son libros de una autenticidad y un coraje moral poco comunes y, en su manifiesta y enérgica parcialidad, altamente representativos (Nora, 1963: 93-94).

Otros detalles de esta peculiar novela de postguerra serían la consciente huida de la realidad cotidiana, la desmembración temática y la expresión barroquizante, falsamente culterana, retórica y florida (Nora, 1963:8).

\section{ESTRUCTURA. TRAMA}

La estructura se organiza en los siguientes elementos conformados por partes: señaladas por el autor con el ordinal correspondiente (coinciden con etapas históricas: 98, guerra civil, etc.) y apartados: separados por el escritor mediante un espacio en blanco. Se trata de unidades temporales similares con cambio de espacio; cambio de tiempo -pasan los días- en el mismo espacio; cambio de espacio con cambio de tiempo.

Primera parte: época de 18983: Apartado 1: a (25-30), b (30-37); apartado 2: a (38-45), b (45-48); apartado 3: a (49-51), b (51-53); apartado 4: a (54-57), b (5759), c (59-62).

3. La numeración que sigue a las partes, como en las citas posteriores, se refiere a las páginas según la edición de Raza (1997). 
Corre el verano de 1897. El Pazo de los Andrade ${ }^{4}$, en Galicia, se dispone a recibir a su propietario, el marino Pedro Churruca, que regresa de uno de sus viajes profesionales. Su esposa, Isabel, y sus hijos, Pedro, Isabelita y José (Jaime, el pequeño apenas tiene dos años), se regocijan por la llegada y acuden al puerto, como tantas personas del pueblo, para dar la bienvenida a los navegantes y celebrar la buena nueva.

Pedro Churruca, tras llegar a tierra, comunica a un anciano del lugar que su nieto no regresa porque murió en acto de servicio. La ermita del Cristo de los Navegantes acoge a la familia que ofrece su acción de gracias. Mientras tanto, doña Isabel practica la caridad con el vecindario y los niños se han mostrado en sus juegos y diversiones de acuerdo con su genio y personalidad. Pedro, el mayor, da a entender que no seguirá la profesión paterna y se muestra insensible ante el sufrimiento de los animales.

En su casa, Pedro Churruca se reúne con sus hijos y les entrega regalos, entre ellos el libro Las Glorias de la Marina Española; hojeándolo, va dando lección sobre cada uno de los pueblos marineros, los navegantes famosos y lo patriótico de sus hazañas. La familia asiste a las fiestas en honor de la Virgen de la Barca de Mugía, en Finisterre, donde se reviven tradiciones religiosas populares. La reunión en la capitanía general evidencia la insurrección en las colonias, Filipinas y Cuba, la intervención de Estados Unidos, la actitud, al respecto, del gobierno español. Pedro Churruca es elegido por sus superiores para mandar un crucero ante la guerra que se avecina. Se despide de su familia y emprende viaje. Cuatro meses después, la incertidumbre se cierne sobre las esposas cuyos maridos marcharon a ultramar porque no llegan noticias oficiales sobre el estado de la marinería. El 3 de julio de 1898, la flota española sucumbe ante la superioridad del adversario. Pedro Churruca muere gloriosamente con el nombre de España entre los labios.

Segunda parte: 1928. Fin de la dictadura primorriverista y etapa republicana. Apartado 1: a (65-66), b (66-69), c (69-78); apartado 2: a (79-81), b (81-82), c (8387), d (87-91).

En el verano de 1898, el Pazo de los Andrade combina los tristes recuerdos de la madre con la ingenua alegría de los niños, ajenos a las consecuencias de su orfandad. Isabel se traslada a Madrid para encauzar los estudios de sus hijos. Doce años después, la visita del almirante Pardo, el mejor amigo del marino Churruca, rememora la figura paterna y queda enterado de la situación familiar. Pedro estudia Derecho y José la carrera de las armas; Jaime, el menor, se ha visto

4. Apellido de un antepasado de quien Franco toma el seudónimo. 
obligado a seguir la tradición marinera ante la renuncia del mayor. Tomando como base la acción española en Marruecos se suscita una agria discusión entre el viejo marino y el estudiante de leyes, que pone en evidencia la distinta ideología de éste respecto a su madre y hermanos.

En el Alcázar de Toledo, José recibe su despacho de oficial, acto al que no asiste su hermano Pedro. Luis Echeverría, amigo de José, sin familia que lo acompañe, es acogido por los Churruca; manifiesta la estima por Isabel. El paseo toledano permite a los nuevos militares hablar sobre la historia y la literatura de Toledo. Se ha celebrado la boda de Isabel con Luis. Pedro solicita a su madre la legítima de su padre, con la oposición de los demás hermanos.

La proclamación de la República convierte a Pedro en candidato a diputado con gran disgusto para la madre. Ésta se refugia en la religión ante el clima de anticlericalismo existente y sufre un atropello en una iglesia cuando se opone a la acción incendiaria de un grupo. El doctor Gómez, amigo de la familia, la trata y aconseja. El clima social republicano la desazona y perturba; la muerte le llega antes de ver a su Patria destruida. Sin la figura de la madre, Pedro se desentiende de sus hermanos mientras que José, profesor en la Academia Militar, y Jaime, ahora fraile de una orden religiosa, se reúnen frecuentemente en casa de Isabel, con Luis y sus hijos. En la primavera de 1936, desde el poder político, comienza la desintegración de España. José muestra públicamente sus ideales patrióticos y es arrestado por la superioridad; la carta del general Moscardó le anima en su conducta. Jaime es destinado a un asilo en Calafell e Isabel sale con los niños para veranear en Bilbao.

Tercera parte: Guerra civil. Desde 1936. Apartado 1: a (95-103); apartado 2: b (104-107), c (107-109), d (109-112), e (112-113), f (113-115); apartado 3: g (116121); apartado 4: h (122-124), i (124-126); apartado 5: j (127-128), k (128-129), $l$ (129-131), $m$ (131-134), n (134-137).

La muerte de Calvo Sotelo fue un asesinato organizado desde el poder político; las consignas rusas tenían como objetivo la implantación del comunismo en España. El 18 de julio de 1936 surgió la aurora de esperanza: el alzamiento de las tropas marroquíes bajo las órdenes de Franco. El gobierno del Frente Popular desencadena la sangrienta revolución que tiene preparada. Las logias y comités revolucionarios reparten entre el pueblo las armas de los parques militares que estaban confiados a los masones.

José, desde Toledo, llega a Madrid. Se incorpora al cuartel de Ingenieros de Carabanchel y se le encomienda llevar una carta al general Fanjul. En las calles, los milicianos saquean a los transeúntes. José es herido en un hombro mientras atraviesa Madrid con un grupo de republicanos. Atendido en la casa de socorro, es reconocido y descubierto por un sanitario con quien coincidió en Marruecos. 
Consigue huir; refugiado en el monumento a Cervantes donde se hace fuerte, es derribado por un golpe en la espalda; llevado a Gobernación, es hecho prisionero. En la cárcel Modelo, José es juzgado por un tribunal popular; vuelto a la galería es asistido espiritualmente por un sacerdote.

Marisol pide a Pedro que interceda por José, condenado a muerte, y le visita en la cárcel. El militar solicita sus condecoraciones y medallas para morir con ellas. Su fusilamiento se convierte en un acto apresurado porque el pelotón huye cuando los aviones inician un bombardeo y el jefe dispara precipitadamente el tiro de gracia. El cuerpo de José es recogido por Marisol; comprueba que vive y recurre a un médico para su curación.

En Bilbao, Isabel conoce por la prensa la noticia del fusilamiento de su hermano al tiempo que una enigmática carta de Marisol sobre el suceso le anima a tener fe. Los milicianos republicanos llegan al hospital de Calafell y hacen prisioneros a los frailes, entre ellos Jaime. Son fusilados en la playa.

Pedro, en Barcelona, dirige los servicios de información republicanos. La detención de un miliciano que transportaba objetos producto de robo sacrílego le permite comprobar que entre ellos aparece la medalla de su hermano Jaime. Los hechos son causa suficiente para que Pedro Churruca comience a tomar conciencia.

José se recupera de las heridas en un sanatorio rojo. Con la ayuda de un médico consigue evadirse y pasar a zona nacional. Ante el jefe de sección de Estado Mayor van identificándose cada uno de los evadidos.

Cuarta parte: Guerra civil. Hasta 1939. Apartado 1: a (141-148); apartado 2: a (149-152), b (152-154); apartado 3: a (155-161); apartado 4: a (162-165), b (165171); apartado 5: a (172-175), b (175-178), c (178-179), d (179-180), e (180-181), $f(181-181)$.

Luis Echeverría está destinado en el frente de Vitoria. Su actitud cavilosa le resta ánimos para seguir combatiendo; su imperiosa necesidad de estar con la familia le inclina a pasarse al enemigo. Llega un longevo voluntario que, procedente de América, quiere incorporarse a la lucha, muertos sus dos hijos en combate, mientras otro, que tiene en la capital a los suyos, se pasa a este bando. Guitarras y canciones animan la noche castrense. Luis Echeverría deserta y, tras presentarse en el cuartel republicano, llega a su casa. Isabel le pide que vuelva con los suyos; el capitán toma la calle en busca de su destino trágico. José, mandando una bandera de la Legión, se presenta a los jefes de los campamentos próximos a Vitoria y se entera de la desaparición de Luis Echeverría. Bilbao es conquistado por las tropas nacionales. Isabel no consigue conocer el paradero final de su marido. Cuando llega a su casa se encuentra a José jugando con los niños. Se habla de Luis, de su destino y de sus hermanos. 
Pedro Churruca recibe la visita de una viuda de militar que se ofrece como espía para revelar secretos a los nacionales; su insistencia y la debilidad del republicano le hace conseguir su objetivo: documentos confidenciales. Descubierto, es condenado a muerte por los suyos y acaba su vida pronunciando Arriba España.

Epílogo: Desfile de la Victoria. a (185-188), b (188-190), c (190-191).

La Cruzada ha triunfado. Un sacerdote explica a José que Pedro murió como un Churruca. Madrid ha sido liberado. La abuela de Marisol la incita a buscar a José. Éste llega a su casa y se arroja en sus brazos. El desfile de la Victoria es presenciado por Marisol, Isabel, sus hijos y el almirante Pardo. José es uno más entre tantos triunfadores.

\section{DEL AUTOR AL LECTOR: A MODO DE «DEDICATORIA» $\mathrm{Y} «$ ADVERTENCIA».}

La focalización de Raza se efectúa como propia de autor omnisciente. Los recursos utilizados en su construcción son diálogos, descripciones, acotaciones, epistolarios y titulares periodísticos, como posteriormente diremos. Sin que aparezcan mencionados con los sintagmas dedicatoria y advertencia al lector, leemos: "A las juventudes de España, / que con su sangre abrieron / el camino de nuestro resurgir. EL AUTOR» (19). Y en página posterior anota un párrafo donde dice:

Vais a vivir escenas de la vida de una generación; episodios inéditos de la Cruzada española, presididos por la nobleza y espiritualidad características de nuestra raza. Una familia hidalga es el centro de esta obra, imagen fiel de las familias españolas que han resistido los más duros embates del materialismo. Sacrificios sublimes, hechos heroicos, rasgos de generosidad y actos de elevada nobleza desfilarán ante vuestros ojos. Nada artificioso encontraréis. Cada episodio arrancará de vuestros labios varios nombres. ¡Muchos! Que así es España y así es la raza (21).

En el inicio, el autor dedica su trabajo a la juventud que dio su vida por España. El sacrificio de aquellos jóvenes muertos por esas ideas es considerado ante una nueva situación. Como puede comprobarse, utiliza un plural concreto («las juventudes») por el singular abstracto para referirse a la juventud; al respecto, la organización juvenil masculina (Organización Juvenil Española: OJE), falangista, uniformada con camisa azul y adornos de yugo y flechas, boina roja, etc., denominaba a sus locales Frente de Juventudes. La sangre, metonimia de connotaciones marciales y religiosas, es símbolo tanto del sacrificio del soldado como del mártir, por cuanto la guerra es también una cruzada. El «resurgir» implica una valoración semántica donde las bondades de lo perdido volverán a ser halladas por cuantos han participado en la acción que ha llevado a la victoria. 
Los factores ideológicos y los sentimentales se unen para sintetizar las esencias de cuanto el novelista quiere transmitir. La oposición se establece entre espiritualidad y materialismo. La retórica empleada en este fragmento, de modo semejante al estilo utilizado en el resto de la obra, se sirve de paralelismos (así es, así es) y enumeraciones (sacrificios sublimes, hechos heroicos, rasgos de generosidad, actos de elevada nobleza), de sinónimos (escenas, episodios) y repeticiones (vuestros, familia, raza) de manera que el tono discursivo pretende actuar sobre el receptor apoyado en evidentes factores conativos (con el uso del tuteo) combinados con los emotivos. Y hasta se atreve a adelantarse al lector para advertirle que no encontrará lo artificioso.

\section{PERSONAJES}

Jaime de Andrade, ficticio autor de la obra, hace entrar a Francisco Franco como mencionado personaje en sus páginas; tal relación esquizoide supone mostrar en variadas ocasiones y con diferentes formas al militar que no sólo se duplica en el personaje principal José, sino que se presenta a sí mismo en párrafos como estos donde se manifiesta su actuación: «un alzamiento de las tropas de Marruecos, a las órdenes del general Franco» (95); su carácter e influencia sobre los demás: «El Generalísimo ha estado esta mañana con nosotros y estaba muy tranquilo» (142); su triunfo: «Los pájaros de acero dibujan en el cielo el nombre del Caudillo de España» (192).

En conjunto, los personajes de Raza, como los de cualquier otra obra, pueden agruparse en principales y secundarios; desde otro punto de vista, esta catalogación puede hacerse atendiendo a la onomástica o, según posición, por oficio, cargo o graduación. Según una elemental estructura social, la composición responde a tres bloques diferentes: a) militares, b) civiles y c) religiosos. En el primero aparecerán diversos grados de la milicia, sea de tierra o mar. En el segundo, hay menciones y referencias a sanitarios, legisladores, jueces y universitarios. En el tercero, además de sacerdotes y frailes se mencionan la Orden de San Juan de Dios y la Compañía de Jesús. Obviamente, entre representantes de a) y b) hay diversos grados de relación que comprende la más amplia estructura familiar, así como vinculaciones profesionales, amistosas, afectivas, etc.

La familia Churruca Andrade está compuesta por Pedro (padre), Isabel (madre) y los hijos Pedro, José, Isabel y Jaime. Por vía política: Luis Echeverría (esposo de Isabel) y su tío, Marisol Mendoza (novia / esposa de José) y la abuela de ésta. Los militares con nombre propio son almirante Cervera, almirante Pardo, capitán de navío Pedro Churruca, capitán Anglada, alférez Torres, sargento Tomás y capitán Domínguez, mientras que los sin onomástica propia son mencionados en función de sus empleos, actividades, etc. Mujeres vinculadas a militares son 
Isabel Andrade, Isabel Churruca, Amiga de Isabel (esposa de militar), Marisol Mendoza y La Generala. Religiosos: Jaime Churruca, padre Palomeque, El Prior, padre Marchena S.J., Capellán. Civiles: a) Con onomástica: Caroliña (campesina), Tomás (cochero), Eufrasia (madre marinero), don Luis (abuelo marinero), Sinda (pescadora), Cholo (hijo de Sinda), Simón (pescador), Tano (portero de Marisol), Pilar Bustamante, José de Sandoval, Joaquín González, Carmen Soler, Mariano Gómez (Médico), doctor Vera, Julio Latorre (profesor de Universidad). b) Sin onomástica: Presidente del Tribunal Popular, Abogado defensor, Fiscal, Juez, Cocinera, Niñera, Criada, Doncella, Carcelero, Muchacho, Un niño.

\section{PRINCIPALES ELEMENTOS TEMÁTICOS}

Raza, como texto escrito (y, de inmediato, como cinematográfico) parece creado para constituirse en alegoría, es decir «ficción en virtud de la cual una cosa representa o significa otra diferente» (DRAE), significación a las que deben añadirse sus variantes en la retórica y en las artes figurativas o plásticas donde las figuras utilizadas o los grupos de estas adquieren representaciones simbólicas. La historia de la familia Churruca (una sublimación de la real tenida por Franco, en especial respecto de los personajes del padre, contable / capitán de navío, y del hermano republicano, Ramón / Pedro) la aventura de José (el propio Franco, representado ficcionalmente en tal personaje y, al tiempo, mencionado como «el Generalísimo» o «el Caudillo») antes y después de la guerra, conforman una simbología de carácter ejemplarizante que comparece, además, en antítesis con la actuación de «los enemigos de España»; por ello, el texto adquiere connotaciones emanadas tanto de personajes y situaciones como de variados conceptos abstractos (raza, patria, deber, honor, etc.) cuya semántica se orienta a constantes significaciones unívocas. De ahí que «la historia del destino personal del individuo sea siempre una alegoría de la problemática situación de la cultura y la sociedad» (Stam, 2001:328), en frase de Fredic Jamenson, y que determinadas y precisas alegorías (básicamente aquellas que utilizan el concepto de nación) remitan a momentos históricos donde la violencia y la represión, la confrontación política y cultural (en el más amplio sentido del término) sean factores poderosos, como mantiene Ismail Xavier (Stam, 2001:328) para constituirse en andamiaje necesario respecto del valor alegórico que se pretende transmitir. Tales alegorías «nacionales», susceptibles de valoraciones y etiquetados diversos, señalan factores primordiales de comportamiento y acción en contextos «de pérdida de objetivos históricos a gran escala» (Stam, 2001:329).

Los conceptos de España, nación, raza y patria, sobreabundan en numerosos ejemplos donde el autor establece su personal discurso con sus correspondientes significaciones a fin de construir la simbología precisa en el entramado argumen- 
tal y temático, bien poniéndolo en boca de sus personajes o en las descripciones explicativas de los hechos narrados. Para José, el objeto de sus preocupaciones en el presente es «España, la zona nacional» (128) y su sangre es «de España», por lo que defiende «la Causa» y no «esa causa vil» (106) mientras que, en referencia al pasado, judíos, moros y cristianos, «al contacto con España se purificaron». Y Jaime, el hermano sacerdote, desde su experiencia religiosa y al amparo de su fe, afirma lo hermoso que es ser español ya que España es «la nación más amada de Dios» (77) y, como consecuencia, la madre declara que «la ayuda divina» nunca le faltará en los «días difíciles» (77); de la misma manera, el indiano voluntario presentado en el frente explica que a sus dos hijos, muertos ya en la guerra, enseñó «a amar a España» (146).

El concepto de nación o de lo nacional supone conservar o recuperar lo que se entiende, desde esas perspectivas, por esencias patrióticas en las que uno de los motivos es la abominación de lo extranjero por cuanto su supresión o eliminación conlleva «el surgimiento de la cultura nacional en su esplendor nativo» (Stam: 2001:330). De esta concepción de la nación como esencia original queda rechazada toda teoría evolucionista o diacrónica que suponga progresiva construcción, diferencial o alterable.

Y raza, título elegido para guión, novela y película, es en primera significación «casta o calidad del origen o linaje» pero también, en sentido metafórico o en añadido oportuno para la alegoría, «rayo de luz que penetra por una abertura» (DRAE). Este parecen recibirlo los patriotas, es decir aquellos que sienten la patria - «tierra natal o adoptiva ordenada como nación a la que se siente ligado el ser humano por vínculos jurídicos, históricos y afectivos» (DRAE) - o su llamada cuando estos consideran que está en peligro. En boca del marino Churruca, según cuenta a sus hijos, los almogávares son los miembros del cuerpo social elegidos para empresas superiores, como a él mismo le ha sucedido, generalmente cuando el destino de la patria peligra, como ocurrió con sus gloriosos antepasados, quienes dieron la vida por ella; son gentes de una raza superior pero pueden pertenecer a cualquier estrato social, incluso al más humilde; en estos casos, la metáfora del rayo de luz es agente activo que ilumina su corazón y les obliga al destino. Si por la Patria «todo es poco» (147) y «el bien hay que hacerlo a la Patria» (146), Luis, el militar, marido de Isabel, «cayó por la Patria» (168) y tanto el nuevo recluta demostró ser «un gran ejemplar de la raza» (160) como los voluntarios sudamericanos, que «buena raza tenían» (146), y su padre don Joaquín González, quien vino de América «ante el peligro de la Patria» (146) y a quien rinden el afecto «que la Patria le debe», le permite decir al capitán Anglada: «Esta es la raza, la que llena de alto contenido la palabra Hispanidad» (147).

Anales, 21, 2009, pp. 213-230 
De modo similar se utilizan conceptos como deber, honor y lealtad. El primero supone estar obligado a algo según lo establecen distinto tipo de leyes, tales como las divinas, las naturales o las positivas. Consecuentemente, implica cumplir obligaciones vinculadas al respeto, la gratitud o motivos semejantes. En Raza este término viene escrito con mayúscula o con minúscula, según se entienda el valor de su utilización y el contexto en el que se use. Para Churruca y su esposa, Isabel, «el Deber» (52) supone, recién llegado de allende los mares, separarse nuevamente de la familia porque la Patria le llama, al igual que su antepasado Cosme Damián «exhortó a todos a cumplir con este Deber» (42), el almirante Cervera explicó que «las razones desaparecen ante el Deber» (60) y el capitán de navío aseguró a los suyos que sólo les quedaría su «propia estimación, el concepto del Deber» (50). En el ámbito familiar, cuando Pedro reclama la legítima de su padre y sus hermanos se oponen, la madre, doña Isabel, sentencia que «la razón es nuestro derecho y la bondad nuestro Deber» (82), al igual que el seguimiento de la tradición marinera por un miembro de la descendencia no es otra cosa que cumplir con «nuestro Deber» (82). Tanto en unas situaciones como en otras se producen «satisfacciones íntimas» porque, en ambos casos, se produjo «el cumplimiento del Deber» lo que equivale al cumplimiento del «Servicio a la Patria» (80).

El honor conlleva en su significación una doble vertiente que alude tanto a la cualidad moral que impulsa al cumplimiento de deberes que afectan a uno mismo o a los semejantes como a «la gloria o buena reputación que sigue a la virtud, al mérito o a las acciones heroicas, la cual trasciende a las familias, personas y acciones mismas del que se las granjea» (DRAE). A Luis, el cuñado pusilánime a quien se le cierra esa metafórica abertura por donde entra la luz, José tiene que advertirle acerca de los sacrificios que entraña el Deber y de cómo se olvida dada la incomodidad de su ejecución; por ello le increpa: «Hay que buscar el camino del Honor» (88); sin duda, esta norma la aprendió de su padre y éste del ejemplo dado por don Álvaro de Bazán, ya que «desde entonces la Marina conserva como preciada reliquia lo que nadie puede arrebatarle... el Honor» (41-42). Pero las exhortaciones del cuñado caen en saco roto; entre el deber militar y la familia, Luis se inclina por la segunda; el novelista, Jaime de Andrade, no perdona la cobardía en un miembro del Ejército; la desaparición del evadido es sinónimo de muerte pero sobre todo de olvido y de pérdida del honor. Isabel aclara a su hermano José cómo se produjeron los hechos y cuál fue su reacción: «Sólo pedía a Dios que me lo devolviese con Honor... yo lo eché de aquí... creí que había hecho bien, que ese era mi Deber» y éste contesta: «Ese era el Deber. Otra cosa hubiera sido el deshonor» (167).

La historia real quedará modificada por la oficial, según las explicaciones que José ofrece a Isabelita, su sobrina, haciéndole ver que el amor a la familia 
fue la causa por la que el padre atravesó las líneas del frente y consiguió llegar a su domicilio; al regresar, la suerte no estuvo de su lado y así encontró la muerte quien en su profesión había destacado por sus valores y pericia. Por si no le quedara claro a la jovencita, el militar pone especial énfasis en su requerimiento y añade: «Desde hoy, sólo debes (sic) recordar que os quería mucho y que fue un gran soldado. Guárdale el culto que merece y olvida la noche en que su cariño lo arrastró al loco empeño de visitaros. El Deber os impuso, a tu madre y a ti, el más grande de los sacrificios. Cayó por la Patria, y ésta es la verdad histórica» (168).

De la misma manera, Pedro, el hermano republicano, la oveja negra de la familia, se preguntará si su deber es salvar a su hermano, Jaime, el fraile, cuando va a ser fusilado, y, de modo semejante, Carmen Soler, le increpará («¿Dónde está su Deber?», 174) para que le entregue los planos que de un bando pasarán al otro; cumplida la solicitud, Pedro morirá contento, como buen Churruca, porque ha actuado según su «Deber» (181).

La lealtad se entiende como el cumplimiento de cuanto exigen las leyes relativas a fidelidad y honor incluido el sinónimo «hombría de bien» (DRAE). Marisol, la ¿novia? de José le ha salvado la vida tras el frustrado fusilamiento por los milicianos y éste le agradece: «iQué buena y qué leal» (110); del mismo modo que Tano, el portero, salvador también, es calificado por ella como «leal» y el «más fiel de los servidores» (112).

La sublevación militar contra la República recibirá los nombres de Movimiento (Nacional) y Alzamiento y así será denominada por Jaime de Andrade, pero como al tiempo implica también una defensa a ultranza de la religión católica y de cuantos profesan su fe, religiosos y seglares, este levantamiento deja de ser sólo una cuestión bélica para adquirir características de Cruzada, es decir, de lucha contra los infieles, comunistas o abanderados del mismo en sus distintas variantes, además de liberales, masones, judíos y «demás ralea» (en frase hecha de la época). A las órdenes del general Franco se produce «un alzamiento de las tropas de Marruecos» que de inmediato se extiende a Cádiz y Sevilla (95); estas «tropas nacionales» formadas por «compañías sueltas» entran en las poblaciones dominadas «con ese aire tolerante de los triunfadores» (163); estos almogávares de 1936 mantienen las esencias patrias que desde siempre les caracterizaron lo que permite al militar Anglada recriminar al enemigo incurrir en el error ya cometido «antes del Movimiento: considerar estas virtudes que fueron y son generales» (148). Llegado 1939, la «Cruzada ha triunfado» (185); Roma, a sabiendas del sacrificio ejercido, bendice a los nuevos mártires que, como los antiguos, mueren «cantando a nuestro Dios y perdonando a sus enemigo» (170) y Madrid se viste de gala «por primera vez después de la Cruzada» (190).

Anales, 21, 2009, pp. 213-230 
Las acciones bélicas llevadas a cabo en frentes y ciudades han tenido otros combatientes además de las tropas nacionales: voluntarios hispanoamericanos (como los González, padre e hijos), falangistas y requetés; nada se dice de los batallones italianos y de las fuerzas alemanas. El ejército tendrá el principal protagonismo en la sucesión de los hechos mientras que el mencionado partido político, brazo derecho de los rebeldes, quedará, narrativamente hablando, en un segundo plano donde el atuendo y la indumentaria, a modo de nota colorista, destaca por encima de las actuaciones tanto en el frente como en la calle; así, «los soldados falangistas saludan» (157); esos soldados del Requeté junto a los de la Falange, «con boina y con camisa azul van y vienen entre las tiendas» (142) en el frente de Vitoria.

Frente a ellos y contra ellos, civiles y militares rojos junto a brigadistas internacionales en defensa de la República y contra el fascismo aniquilador. Obviamente, estos personajes están vistos y descritos bajo el prisma ideológico nacional; por ello, los milicianos rojos se presentan «despechugados y sucios» (101) y en «bárbara y soez algarabía» (123), José no puede sino mirar «con desprecio a aquella turba» (101) y quedarse estupefacto con «los gritos e improperios de furias y marimachos» (102). Si la referencia es a una entidad oficial, sea el Estado Mayor de Bilbao, sea la habitación de un sanatorio, las botellas y colillas por el suelo están a tono con las gentes «desharrapadas, en mangas de camisa» (152). Rojo es el adjetivo predominante para calificar al variado enemigo, en singular o plural, a las diversas situaciones, a las tropas republicanas: «las últimas horas del dominio rojo» (162) son también las últimas del «cabecilla rojo de Bilbao», de la «ola de crímenes de las hordas rojas» (172), de «la barbarie roja», que ha volado los «hermosos puentes sobre la ría, ilusiones y trabajo de varias generaciones» (163) y que se retiran derrotados «en desfile desordenado... en su rostro el terror de los vencidos» (172). La actuación de las Brigadas Internacionales se ofrece en su derrota, allá en el Pingarrón donde, según el ayudante del general, «quedaron desechas» (143) y según el capitán Anglada se le está prestando un buen servicio a Europa «purgándola de los indeseables de todas las revoluciones» (143) porque, dicen, son «lo mas duro e indeseable del hampa europea» (156).

Más allá de estas singularidades, Raza contiene abundantes factores donde el didactismo y la historia, personal o general, se combinan a gusto del escritor y en ocasiones con tal proliferación de nombres que deja corto a un manual o libro con fines docentes (no en balde, Sáenz de Heredia, el director de la película homónima, al plantear el guión dijo que eliminaría de él cuanto se pudiera encontrar en el Espasa; claro que aún no sabía quién era el autor del mismo); así, las glorias de la marina española le llevan al autor varias páginas que se inician 
con los fenicios y acaban con los Churruca; atención merecen cartagineses y arábigo-andaluces, catalanes y castellanos; diversos nombres propios aparecen precisados: Roger de Flor (caudillo de los almogávares), Colón, Magallanes, Cortés, Pizarro, además de la Armada Invencible junto a navíos como el San Juan Nepomuceno o el Trafalgar (39-43). Lo mismo le ocurre al personaje principal, José, que suspira por ejercer la docencia y al tiempo poner en duda a quienes por profesión la ejercen: «Si algún día la suerte me depara enseñar a una juventud esto será lo que yo he de inculcarles. Ayudarles a formar su carácter. ¿Qué saben hoy de nosotros nuestros profesores?» (74). Y, siguiendo el ejemplo ocurrido a un antiguo cadete, aconseja escribir cien veces aquello que, por su ejemplaridad, no debe olvidarse (71). La academia militar y sus procedimientos han forjado soldados ocasionalmente convertidos en héroes y Toledo, donde está ubicada, le permite repasar los nombres que la Historia ha hecho legendarios: Recaredo, Berenguela, Blanca de Borbón, Alfonso VI, El Cid, y hasta el mismísimo Cervantes, quien, según José, «presidió nuestra lucha» (168), por lo que en cierta ocasión compró hasta seis ejemplares de La ilustre fregona para regalar a sus compañeros, en homenaje al gran autor. Las mujeres antes referidas están relacionadas con sus esposos (Alfonso VI, Pedro I) mientras que otras, doña María de Padilla o doña María Pacheco, quedan mencionadas, dada su anómala conducta, como la que mantuvo «amores impuros», la primera, y a quien «las aguas del Tajo le ofrecieron protección para su huida» (72), la segunda. Tales referencias se efectúan bajo precisos matices que implican una específica concepción sobre la mujer, su situación social, su dependencia del hombre, etc.; así puede leerse: «las galerías, colgadas de tapices y viejos terciopelos, se adornan con la presencia de centenares de muchachas» (70); las que prestan servicio a su causa son «esas buenas mujeres de nuestro pueblo, todo corazón y espontaneidad» (116), como la hermana de Tano, mientras que las milicianas del bando contrario son tildadas de «marimachos» (102) que saquean a los pacíficos transeúntes (99). Y si es Pilar Bustamante, la falangista huida del Madrid rojo, sacrificó su cabello «haciendo de muchacho» para pasar desapercibida; ya en el frente nacional, el militar de turno da la orden para que le faciliten ropa adecuada, porque estará deseando «recuperar su feminidad» (135). Y a Isabel, quien en frase coloquial expresa «QQué tontas somos las mujeres!», el doctor Gómez le dice: «Cuando se está en la reserva, mi querida señora, no se combate; eso queda para nosotros, a quienes corresponde por sexo y edad» (85). Y en línea semejante de pensamiento, José se explica: «lo razono como una sensibilidad femenina ante la muerte fría del mártir de una causa amada» (170).

Ya hemos dicho que los profesores no reciben buena consideración en la novela. El propio José se interroga sobre el conocimiento que estos tienen de los 
jóvenes, incluidos los docentes de la Academia. Y Pardo, el compañero y amigo de Churruca, no sabe de qué sorprenderse más, si de la «infamia de los profesores», de la «conformidad de la juventud» o del Ateneo en el que «buenas cosas se cuecen» (68-69) al igual que Isabel, la madre, resignada a ver a su hijo ingresar en la Universidad, donde, según su marido, «venía fomentándose la decadencia de España» (67). Dos entidades severamente enjuiciadas.

\section{ASPECTOS ESTILÍSTICOS}

Distintos tipos de lenguaje se presentan en la novela. El epistolar se pone de manifiesto en dos ocasiones: en la carta del general Moscardó a José Churruca (89) y en la firmada por Marisol dirigida a Isabel (120-121), mientras que los titulares periodísticos tienen acomodo en el texto narrativo tal como en cita textual se indica: «Los Estados Unidos culpan a España de la voladura del Maine», «Grandes manifestaciones en Nueva York», «Barcos norteamericanos salen para las Antillas», «Nuestra Patria, calumniada» (54). Nótense las connotaciones negativas que acompañan a los titulares. La prensa, junto a esas sociedades mencionadas (Ateneo, Universidad), no es bien vista por el autor.

Los usos populares entre los franquistas se aprecian en frases como «mucho hule» por el Pingarrón (156), «canela fina» (157), en referencia al Tercio de Montejurra, «buena solera» para aludir al segundo de Flandes (157); se usan despectivamente masón y mambís e insurrecto (65) cuando se aplica a las colonias sudamericanas sublevadas; de la misma manera se utilizan términos como enano (69), populacho (96) o turba (96). Y en boca de los milicianos, deformaciones lingüísticas como atontaos (98), semos (99), so idiota (123). El lenguaje pueblerino permite al autor aludir al «tonillo» propio de la tierra gallega, tal como se expresa Caroliña, quien viste el típico traje campesino y pronuncia señurita o mestra (27) mientras que con la jerga marinera hace un guiño al lector para aludir al giro de las velas que «bracean las del palo trinquete hasta flamear y, al fachear» (35).

El uso del adjetivo tiende a mostrarse antecediendo al sustantivo tal como lo hace para referirse al «severo pórtico», «la carcomida piedra», «el viejo escudo», «la verde pradera», «la señorial mansión» (26) todo ello en el mismo párrafo dedicado a describir el pazo de los Andrade. En este paraje y en otros semejantes, los elementos visuales acogen a los puramente auditivos de manera que el lector atento puede oír tanto el chirriar de cigarras como el quejido de un carro, el tañido de la campana y los pasos precipitados de las zuecas (26) y del mismo modo el olfato permite saber que huele a campo o que «el mar perfuma el aire» (48). El término burgués, al margen de su distancia respecto a aristócrata y en contraposición a proletario, tiene habitualmente el valor de la acepción carente de afanes espirituales o elevados, materialistas en suma, tal como se comprueba 
en los sintagmas «le han tocado tiempos burgueses» (80) que la señora Churruca lanza al señor Echeverría, el invitado a la boda de su sobrino a quien ayuda económicamente porque la profesión de militar no da para mucho, según él mismo comenta; será la «masa burguesa» la que contemple el «sacrílego incendio» (83) con indiferencia.

Las metáforas suelen ser elementales en su construcción y sencillas en la relación entre sus términos; así, el «sol de fuego» se levanta en el horizonte «dorando el paisaje» (114) y se convierte en «disco de fuego» cuando se sumerge en el mar (47), mientras los aviones «roncan en el aire» (192) y la ría se presenta como una «superficie de raso» (35); las aguas se convierten en «surtidor de espumas» (35) y las olas «levantan surtidores de espuma» (53); los cabellos son «hebras de plata» (66) y las inquietudes se presentan como «una madeja» $(26)^{5}$.

Recursos propios de la novela parecen estar especialmente utilizados en sus funciones de guión, entendidas como observaciones o acotaciones, según se observa en expresiones explicativas o definidoras de situaciones, movimientos, acciones: «saltando y palmoteando» (27), «inclinándose un poco y poniendo las manos sobre los muslos en ademán admirativo» (28), «enseñándole el pájaro que mantiene en su mano, atado por una pata» (29).

Los factores temporales vienen expresados por las cifras correspondientes, tal como «estamos en el año 1897» (25), «han pasado cuatro meses desde la partida de su esposo» (54), «doce años han transcurrido desde la muerte de Pedro» (67); «entramos en la primavera de 1936» (87); también por adverbios que suelen repetirse al encontrar cómodo su funcionamiento o por utilizar estructuras semejantes: «mientras esta escena tiene lugar» (35), «mientras esto sucede» (107 y 124); el general de Marina «se enjuga furtivamente una lágrima» (51) al igual que Isabel «furtivamente se seca una lágrima» (52).

La retórica del escritor le hace usar en paralelo los estados de ánimo de los personajes con el comportamiento de la naturaleza; así, la despedida del marino Churruca, acaso sabiendo que ya no volverá más a su tierra, la describe el autor de este modo: «El desfile hacia el puerto es triste y penoso; la lluvia ha convertido los caminos en un barrizal, y los vientos del norte agitan un mar plomizo» (53); del mismo modo, cuando la familia abandona el pazo se nos dice: «Un frío viento norteño desnuda los árboles añosos del jardín cuando Isabel abandona, con sus hijos, el viejo solar» (66). Ocasionalmente, se establece relación entre elementos temporales y moralidad de las personas: «Son esas horas primeras de

5. Si no pareciera un dislate, diríamos que de Andrade deja oír ciertos ecos lorquianos en determinadas expresiones suyas o de sus personajes: «Los olivares están negros de muertos» (143), «iQué rápidos pasan los días! ¡Qué sucesión de intensas emociones! (38).

Anales, 21, 2009, pp. 213-230 
la mañana, durante las que sólo discurren por las vías las gentes trabajadoras» (116); y esta contestación: «De noche, no; señor. En este barrio peligraría. Muy temprano, que es cuando circulan las gentes trabajadoras» (116).

Las repeticiones y cacofonías suelen darse con frecuencia en un texto que carece del pulimento literario: «se detiene al lado de una pequeña casa, en la que un pequeño banderín señala» (155); «él era muy minucioso... se hizo una minuciosa descubierta» (160); «algunos jefes...en algunos momentos» (162); «una casa con una placa con el rótulo» (129). De la misma manera, una catarata de gerundios puede inundar un largo párrafo que no ha encontrado un signo separador para amortiguar el elemental barroquismo sintáctico: «batiendo los emplazamientos [...] extendiéndose hacia la ciudad [...] sumiéndola en una densísima [...] contribuyendo a» (162).

El eufemismo (término, frase, oración) le sirve para ocultar hechos negativos referidos a la persona; ya hemos mencionado la descripción utilizada para con doña María Pacheco; de la misma manera, la cobarde huida del capitán Echeverría queda mencionada de esta manera: «Paradas y sobresaltos, acostado sobre el suelo encharcado, presiden la lucha contra el destino trágico» (154).

\section{BIBLIOGRAFÍA}

BASANTA, Ángel (1981), La literatura de la posguerra: la narrativa, Madrid, Cincel.

GUBERN, Román (1977), Raza: un ensueño del general Franco, Barcelona, Ediciones 99.

JAIME DE ANDRADE (1942), Raza, Madrid, Ediciones Numancia. Ediciones de la Vicesecretaría de Educación Popular. Reed.: 1945.

- (1997), Raza. La novela que escribió Franco, Int. Ricardo de la Cierva, Barcelona, Planeta-Fundación Nacional Francisco Franco.

NORA, Eugenio de (1963), La novela española contemporánea, Madrid, Gredos.

SOBEJANO, Gonzalo (1975), Novela española de nuestro tiempo, Madrid, Prensa Española.

STAM, Robert (2001), Teorías del cine, Barcelona, Paidós.

Fecha de recepción: 28 de junio de 2008

Fecha de aprobación: 15 de octubre de 2008

Anales, 21, 2009, pp. 213-230 